\title{
Seismic imaging of the western Iberian crust using ambient noise: Boundaries and internal structure of the Iberian Massif
}

\author{
Graça Silveira a,b,* Nuno Afonso Dias ${ }^{\mathrm{a}, \mathrm{b}}$, Antonio Villaseñor ${ }^{\mathrm{c}}$ \\ a Instituto Dom Luiz (IDL), 1749-016 Lisbon, Portugal \\ b Instituto Superior de Engenharia de Lisboa (ISEL), 1959-007 Lisbon, Portugal \\ ${ }^{\mathrm{c}}$ Instituto de Ciencias de la Tierra Jaume Almera, CSIC, 08028 Barcelona, Spain
}

\section{A R T I C L E I N F O}

\section{Article history:}

Received 5 March 2012

Received in revised form 31 October 2012

Accepted 30 December 2012

Available online 10 January 2013

\section{Keywords:}

Seismic interferometry

Ambient noise

Surface-wave tomography

Iberian Peninsula

Iberian Massif

\begin{abstract}
A B S T R A C T
We present new Rayleigh-wave dispersion maps of the western Iberian Peninsula for periods between 8 and $30 \mathrm{~s}$, obtained from correlations of seismic ambient noise, following the recent increase in seismic broadband network density in Portugal and Spain. Group velocities have been computed for each station pair using the empirical Green's functions generated by cross-correlating one-day-length seismic ambient-noise records. The resulting high-path density allows us to obtain lateral variations of the group velocities as a function of period in cells of $0.5^{\circ} \times 0.5^{\circ}$ with an unprecedented resolution. As a result we were able to address some of the unknowns regarding the lithospheric structure beneath SW Iberia. The dispersion maps allow the imaging of the major structural units, namely the Iberian Massif, and the Lusitanian and Algarve Meso-Cenozoic basins. The Cadiz Gulf/Gibraltar Strait area corresponds to a strong low-velocity anomaly, which can be followed to the largest period inverted, although slightly shifted to the east at longer periods. Within the Iberian Massif, second-order perturbations in the group velocities are consistent with the transitions between tectonic units composing the massif.
\end{abstract}

(c) 2013 Elsevier B.V. All rights reserved.

\section{Introduction}

The lithosphere of the Iberian Peninsula and its margins has been formed through a number of processes of collision and extension. The main event of Iberian lithosphere formation was the Variscan Orogeny, when several continental blocks collided between early Devonian and Late Carboniferous, its current expression identified as the Iberian Massif. Composed by rocks with ages ranging from the Upper Precambrian to Upper Carboniferous, the Iberian Massif outcrops in Central and Western Iberia; to the southeast and northeast of Iberia the main features are the alpine chains of the Betics and Pyrenees and the associated Neogene Guadalquivir and Ebro basins. To the east the Iberian Massif is limited and partially covered by the Cenozoic basins associated with the Douro/Duero and Tagus rivers, while to the west and southwest it is limited by the Lusitanian and Algarve Mesozoic basins (Fig. 1).

The main tectonic units of the Iberian Massif, comprising a transect of the Ibero-Armorican Arc branch of the Variscan Belt, are (Fig. 1): the Cantabrian Zone (CZ), the West Asturian-Leonese Zone (WALZ), the Galicia-Tras-os-Montes Zone (GTMZ), the Central Iberian Zone $(\mathrm{CIZ})$, the Ossa Morena Zone (OMZ) and the South Portuguese Zone (SPZ). GTMZ consists of a pile of allochthonous thrust sheets, of high metamorphic grade rocks, lying over CIZ and WALZ autochthon. There is some debate on the evolution of the Variscan Orogeny, regarding

\footnotetext{
* Corresponding author at: Instituto Dom Luiz (IDL), 1749-016 Lisbon, Portugal. Tel.: + 351217500812

E-mail address: mdsilveira@fc.ul.pt (G. Silveira).
}

the several units composing the Iberian Massif and on the exact nature of the contacts between them (Dias and Ribeiro, 1995; García-Navarro, 2004; Onézime et al., 2003; Simancas et al., 2001, 2003), but all recognize the contacts SPZ-OMZ and OMZ-CIZ as suture zones. While in the SPZ-OMZ there is the presence of igneous rocks with oceanic affinity (Beja-Acebuches Ophiolitic Complex), the OMZ-CIZ contact is a complex tectonic unit presenting rocks with high metamorphic grade and some mafic content (Fernández et al., 2004). The Lusitanian and Algarve basins are the result of the extension episodes associated with the rifting of the Atlantic during the Mesozoic.

The interaction between Africa and Iberia is characterized by a diffuse convergent margin that originates a vast area of deformation concentrated in the southern and eastern margins of Iberia, the major topographic features being the Betics, Iberian and Pyrenees chains.

The impact of this complex tectonics on the structure of the lithosphere remains poorly known, especially the response of the Iberian Massif. Although the Iberian Massif remained widely unaffected by Africa-Iberia convergence, the anomalous concentration of seismicity observed on the western part of the Iberian Massif (Borges et al., 2001) shows that some deformation is indeed present and not confined to the southern limit. However the exact relationship between the shallow and deeper structures, their lateral extension and the exact role of the Variscan structures are still widely unknown.

Over the last decades, Canas et al. (1988), Badal et al. (1992, 1993 1996), Payo et al. (1992), Corchete et al. (1993, 1995), Lana et al. (1997, 1999), Martinez et al. (2005), among others, derived tomographic models by measuring the dispersion of the fundamental mode 


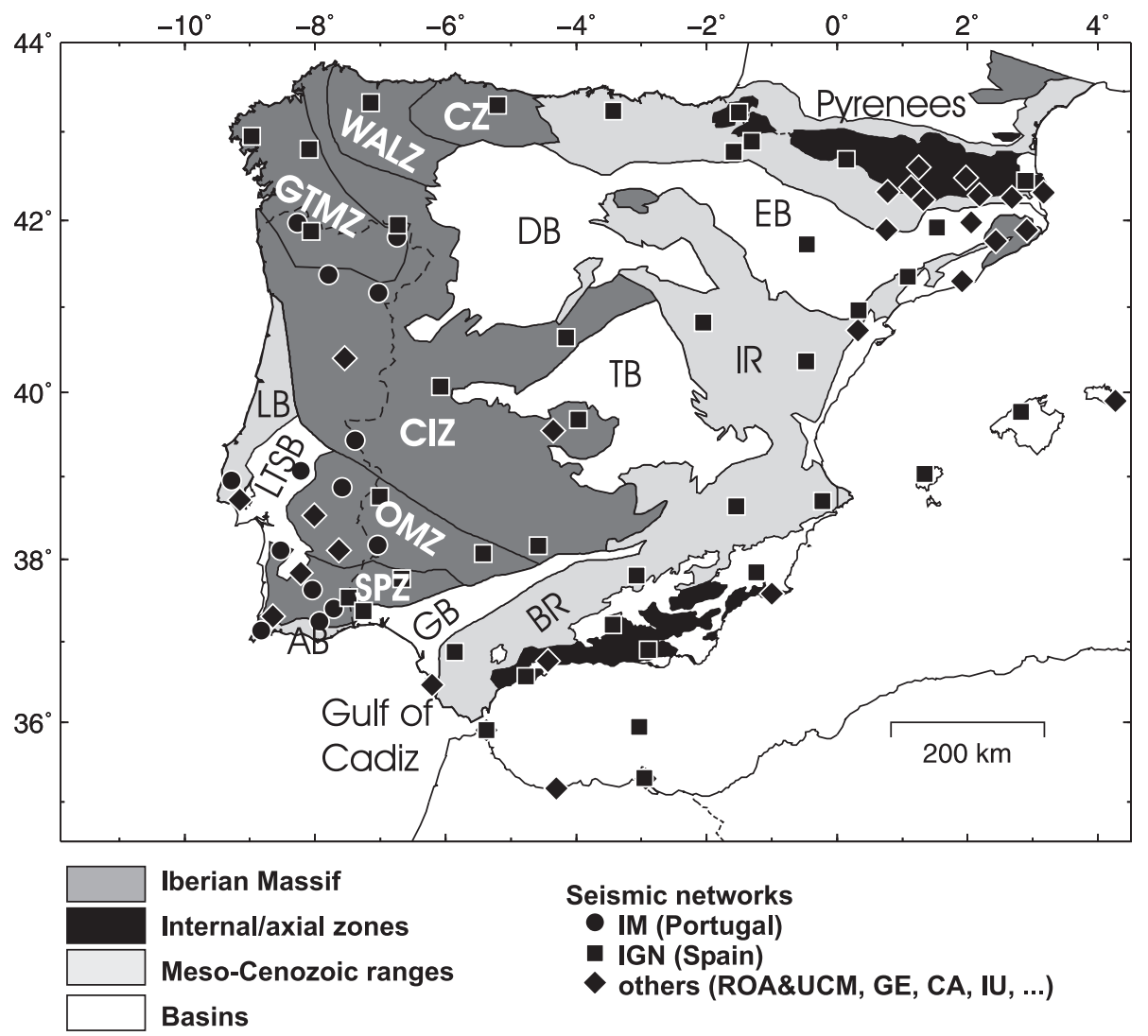

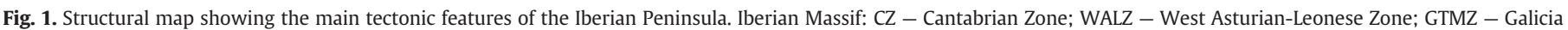

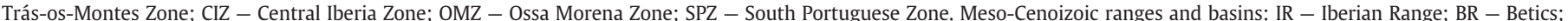

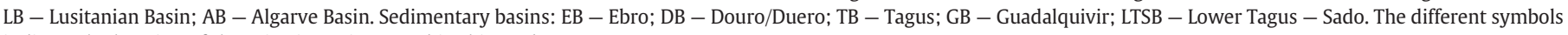
indicate the location of the seismic stations used in this study.

Modified from Vergés and Fernàndez (2006).

of Rayleigh waves propagating across the Iberian Peninsula. Results from these authors generally enable to distinguish an average structure of the main tectonic features beneath the Peninsula, but the limits for the different tectonic units were impossible to retrieve. Several problems like source-receiver geometry, irregular seismicity distribution or, for some methods, low seismicity occurrence did not allow obtaining high-resolution models of Iberian structure using traditional imaging methods.

More detailed knowledge on the deep structure of the crust under Iberia has been provided by several refraction/wide-angle seismic profiles acquired over the last decades (Díaz and Gallart, 2009 and references within). These studies indicate a thicker crust beneath central Iberian Massif and beneath the alpine chains with a progressive thinning towards the Iberian margins, with values ranging from 35 to $40 \mathrm{~km}$ to $\sim 30 \mathrm{~km}$. Beneath western Iberia, the models obtained from the majority of these profiles indicate a three-layer crust, the middle-lower crustal levels indicating fairly stable results, the main differences located at the upper crust. However, in the OMZ there is an indication of a crustal thinning relative to the $\mathrm{CIZ}$ and especially with respect to the SPZ. To the offshore areas of the margins the crustal thinning is gradual, with a smaller reduction gradient towards the SW Iberian margin (Afilhado et al., 2008; Fernández et al., 2004; Gonzalez et al., 1996; Gonzalez-Fernandez et al., 2001).

In terms of the physical properties of the crust, SW Iberia has been studied through magnetotelluric surveys, carried essentially over the SPZ, OMZ and CIZ (e.g. Carbonell et al., 2004; da Silva et al., 2007; Muñoz et al., 2008; Santos et al., 1999, 2002).

The objective of this study is to define the boundaries of the Iberian Massif particularly those that are covered or in contact with recent
(Cenozoic) and older (Mesozoic) basins. Whenever possible, we will characterize second-order structures inside the Massif.

Seismic interferometry/ambient noise surface-wave tomography allows imaging regions with a resolution that mainly depends on the seismic network coverage. Villaseñor et al. (2007) performed the first ambient noise surface-wave tomography of the Iberian Peninsula, which allowed to obtain group-velocity maps between 8 and $30 \mathrm{~s}$ with an unprecedented resolution. However, both spatial coverage and resolution need to be improved. The opportunity to progress with this study comes from the upgrade of the Portuguese National Seismic

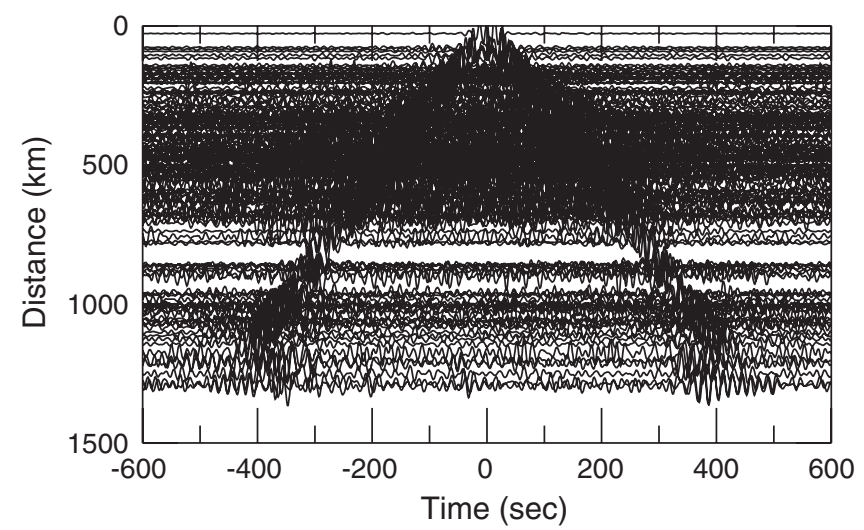

Fig. 2. Result of 12 month ambient noise cross-correlating data for station MORF (Marmelete, South Portugal), with respect to all other stations in the Iberian Peninsula, displayed as seismic record section. 
Network of the Instituto de Meteorologia (IM), following the 2004 Sumatra event, together with other permanent and temporary networks.

\section{Data and method}

For this study we have collected 12 months of continuous seismic recordings (January to December 2008) from about 90 permanent broad-band stations in the Iberian Peninsula (Fig. 1). The main data source was the newly deployed Portuguese broad band seismic network, operated by Instituto de Meteorologia (IM, Portugal), as well as the Spanish National Seismic Network, operated by Instituto Geográfico Nacional (IGN, Spain). Data from the University of Lisbon network (LX), from the Real Instituto y Observatorio de la Armada (ROA, Spain) and stations in the region that are part of global networks have also been included. To better constrain the South Portuguese Zone, we have integrated records from permanent stations in Madeira and Canary islands.

To obtain Green's functions from the cross-correlations of ambient noise and from them surface-wave dispersion measurements we have followed the procedure of Bensen et al. (2007), and therefore only a short summary will be presented here. The first step in the data processing involves removing the instrument response, converting the seismogram to velocity, and applying a pre-processing procedure that reduces the effect of earthquakes and compensates for the spectral characteristics of the ambient noise. We are interested in the period range that includes the primary and secondary microseisms, where ambient-noise energy in the form of surface waves is larger. This is also the optimum period range for the available station spacing and aperture of our network. Therefore we have also filtered the data between 5 and $150 \mathrm{~s}$ to eliminate energy outside our range of interest.
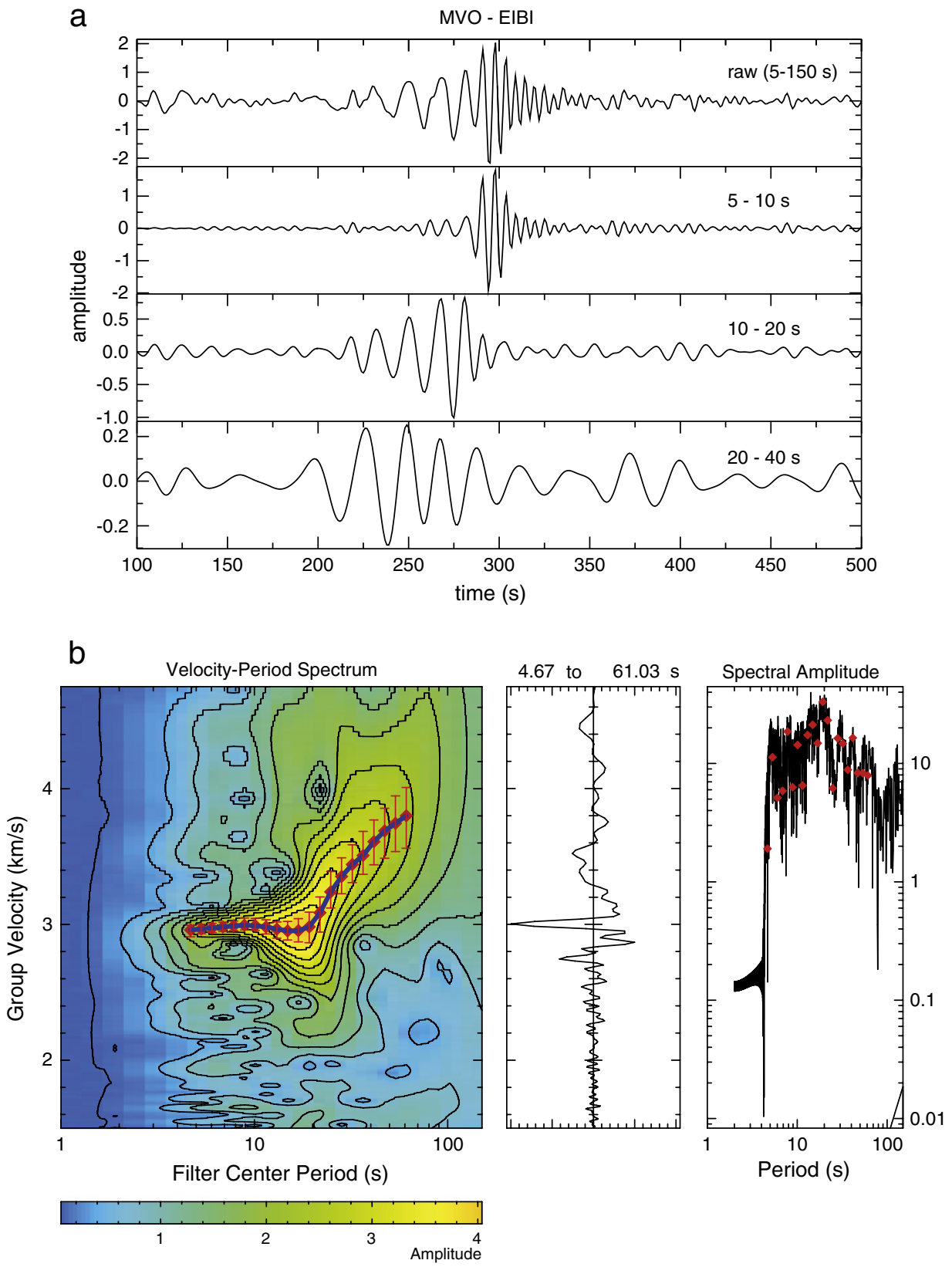

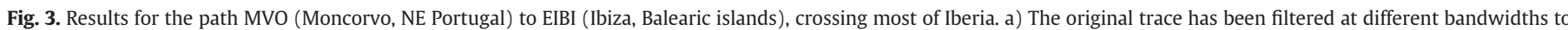
evaluate its dispersive nature. b) Dispersion curve of the fundamental mode Rayleigh-wave group-velocity calculated using FTAN. 
a

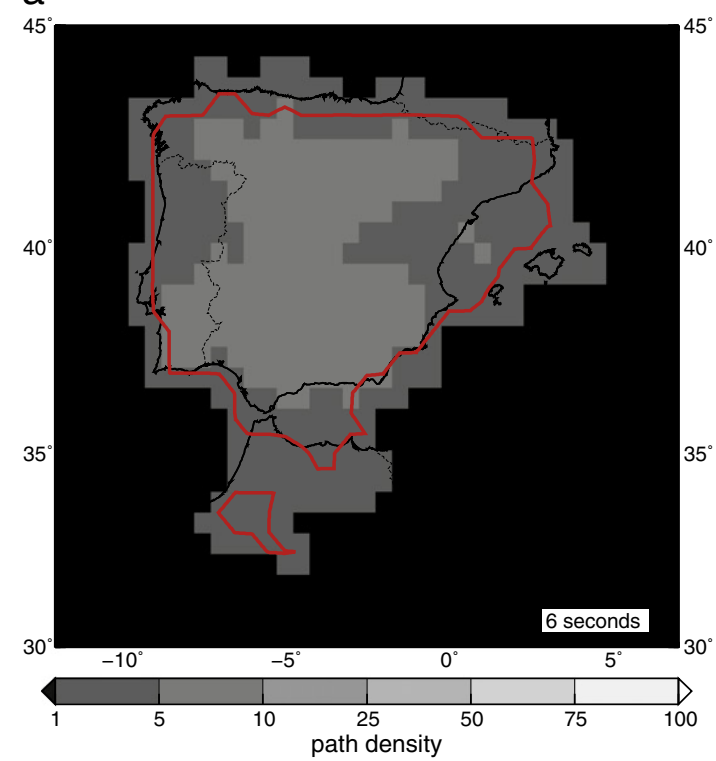

b

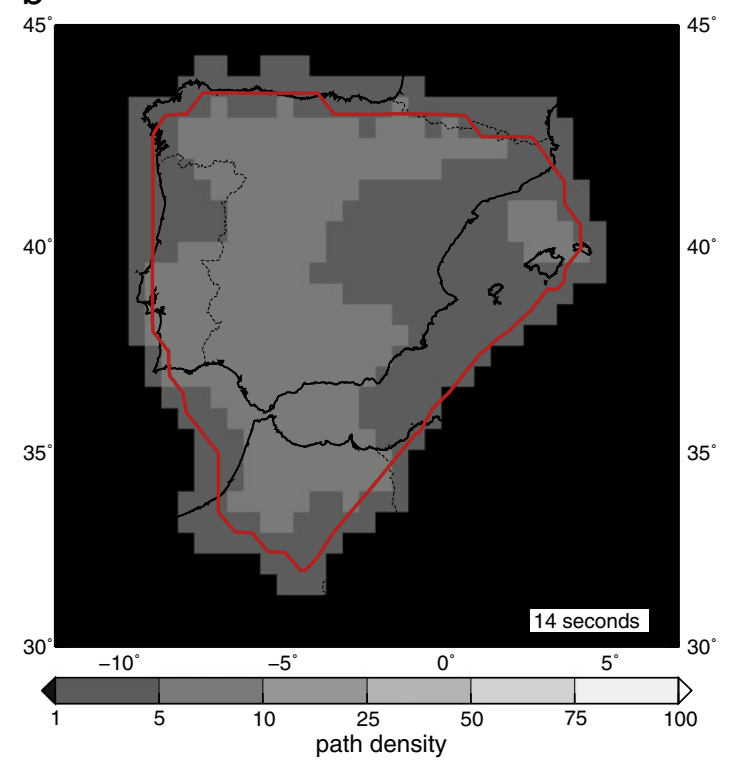

C

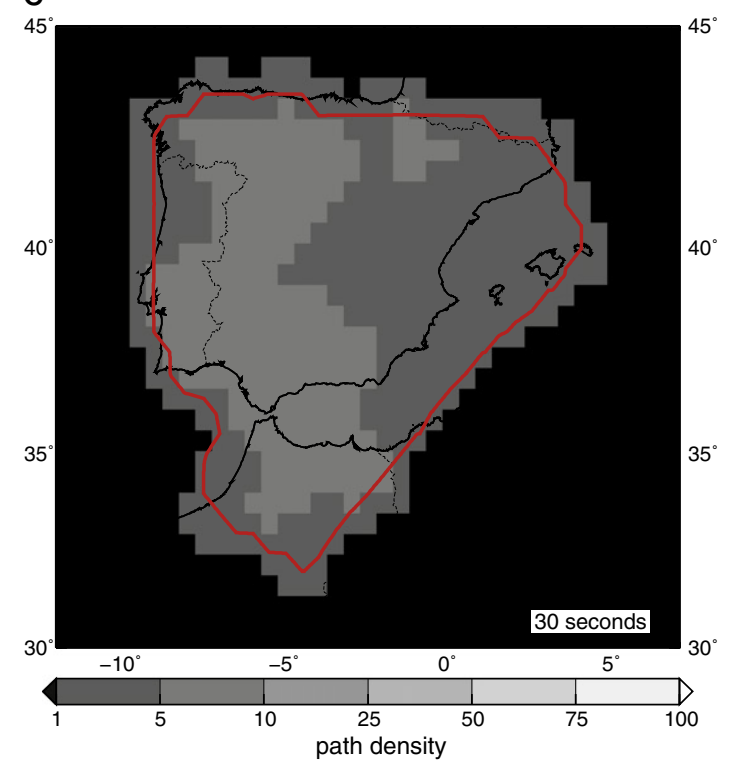

The contamination of ambient-noise recordings by earthquakes and non-stationary noise sources near the stations is partly removed by applying the procedure of "temporal normalization", by computing the running average of the absolute value of the waveform amplitude in a window of fixed length (256 s) and weighting the waveform at the center of the window by the inverse of that average (Bensen et al., 2007). This is followed by spectral normalization or "whitening", which takes into account that the ambient-noise amplitude spectrum is not flat in the frequency band of interest (potentially $1-50 \mathrm{~s}$ or wider). To compensate for this, we divide the Fourier transformed waveform by the smoothed amplitude spectrum, resulting in all frequencies having comparable amplitudes. This broadens the frequency band of the ambient noise signal and reduces the effect of persistent monochromatic sources. All these steps of the processing have been done using 1-day data windows with no overlap as in Bensen et al. (2007). Finally, all the recordings processed using the procedure described above are cross-correlated and stacked for the entire year with the objective of improving the signal-to-noise ratio.

Once computed the inter-station Green's functions generated by cross-correlation of seismic ambient noise, we followed the methodology traditionally used for surface-wave tomography using dispersion measurements. Group and phase velocity dispersion on the Green's functions were measured using the frequency-time analysis (FTAN) methodology (Levshin et al., 1992).

Finally, we apply a 2D tomographic inversion to the selected group and phase velocity measurements for periods between 6 and $30 \mathrm{~s}$ to obtain fundamental-mode Rayleigh-wave group and phase velocity perturbation maps on a $0.5 \times 0.5$ degree grid across the Iberian Peninsula. The tomography method is that of Barmin et al. (2001), which approximately accounts for the spatially extended frequency-dependent sensitivity of the waves by using Gaussian lateral sensitivity kernels. Although the use of spatially extended sensitivity kernels has only a small effect on the estimated maps at the periods considered (Ritzwoller et al., 2002), they help to provide a more accurate estimate of spatial resolution. This scalar quantity, instead of being obtained using the information from the resolution matrix, is determined as follows: for each grid point of the model we constructed a resolution kernel, which is a row of the resolution matrix, and we fit a 2-D spatial Gaussian function to the kernel and identified the resolution as twice the standard deviation of the Gaussian.

\section{Results}

Inter-station cross-correlations between each pair of broad-band seismic stations enabled us to obtain 4278 empirical Green's functions. Fig. 2 shows a record section for the correlations computed between station MORF (in Marmelete, Algarve, SW Portugal) and all other stations. The presence of dispersive Rayleigh-wave pulses is clearly visible in both negative and positive lags of the record section. We also observe the move-out of the pulse arrivals as a function of distance, corresponding to an average velocity of $\sim 3.0 \mathrm{~km} \mathrm{~s}^{-1}$.

The final Green's functions (or cross-correlations) for each station pair are obtained by summing both positive and negative lags (Fig. 3a, top record). The original trace has been filtered at different bandwidths to evaluate its dispersive nature (Fig. 3a), which can be observed in this example by the longer periods arriving earlier than the shorter ones. The energy diagram corresponding to the above Green's function is presented in Fig. 3b, where the fundamental-mode group velocity can be identified.

The quality of each cross-correlation is quantified, as a function of the period, through the signal-to-noise ratio (SNR). Only cross-correlations

Fig. 4. Path density of the data set with $S N R \geq 15$ used to obtain group-velocity maps at 6,14 and 30 s period. 
a

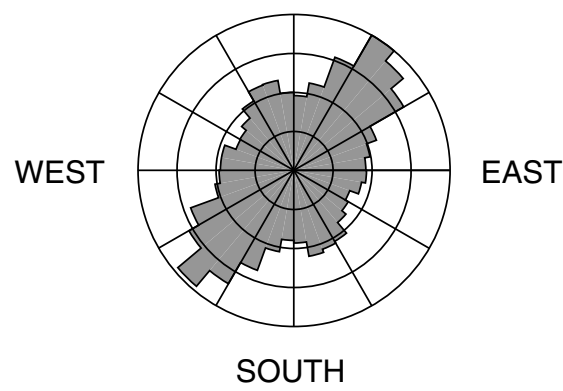

b

$10 \mathrm{~s}$

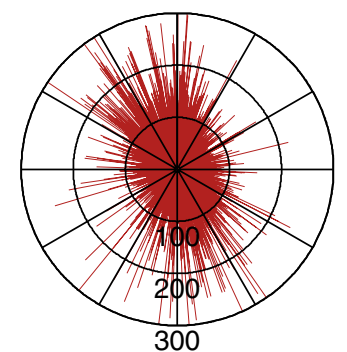

$20 \mathrm{~s}$

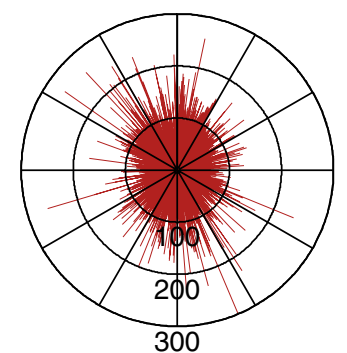

$25 \mathrm{~s}$

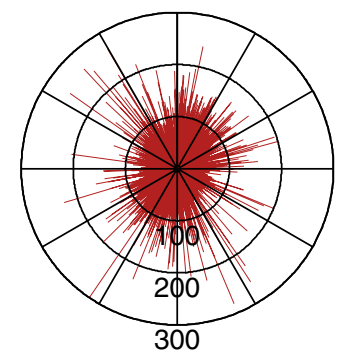

winter
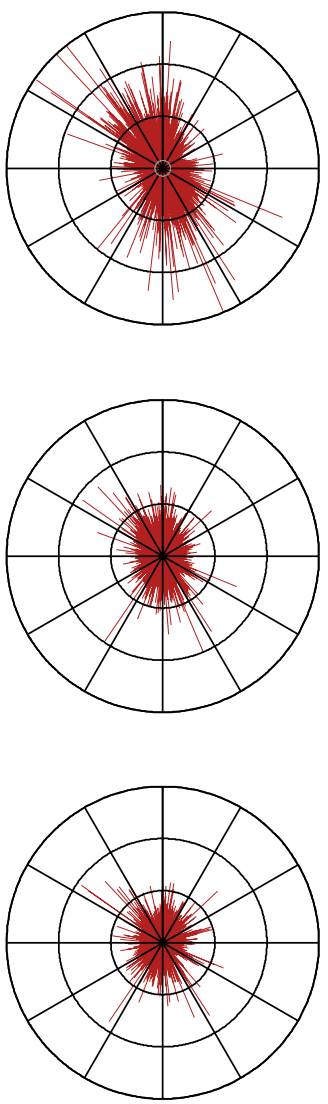

summer
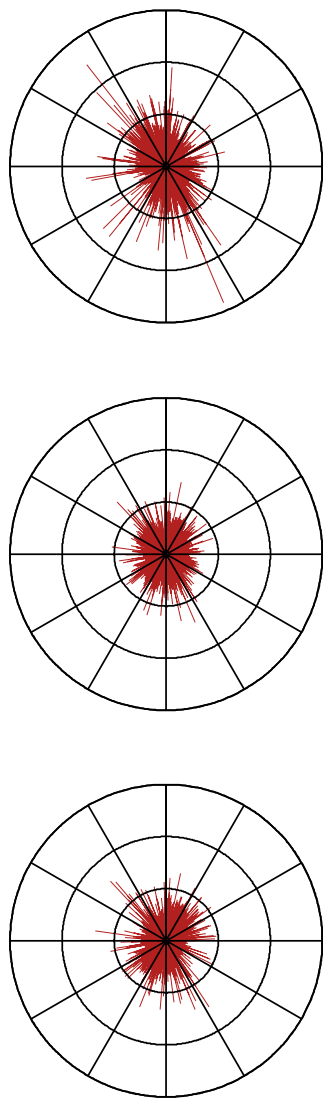

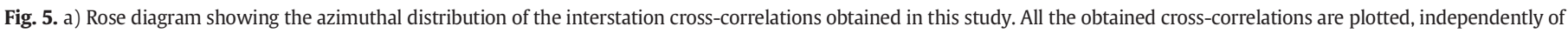

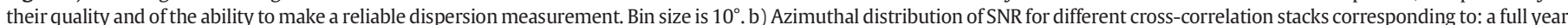

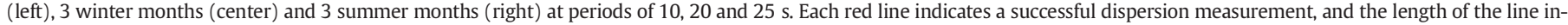

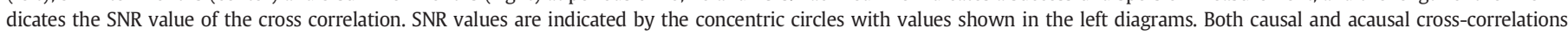
have been included.

with a SNR greater than 15 have been considered for dispersion measurements. This is more restrictive than the value of 10 used by Bensen et al. (2007) and provides accurate measurements for surface wave tomography.

Following these criteria, we obtain a path coverage density for the Iberia which is shown in Fig. 4. Path density (or hit count) is calculated as the number of rays that cross a square cell of $0.5^{\circ} \times 0.5^{\circ}$ centered on each grid node of the model. The red line shown in Fig. 4 encloses the regions with $100 \mathrm{~km}$ resolution or better.

A potential problem in the computation of the noise cross correlations (or empirical Green's functions) is the effect of inhomogeneous illumination of the ambient noise. Yang and Ritzwoller (2008) have addressed this problem and found that, even when the dominant sources of ambient noise are inhomogeneously distributed in azimuth, strong ambient noise emerges from most directions when using recordings that are 1 year in duration as in this study. In Fig. 5 we show the azimuthal distribution of the noise in our dataset. Fig. 5a shows the azimuthal distribution of all the interstation paths in our dataset that have produced crosscorrelations (independently of their quality). There is a slight predominance of the NE-SW direction, but the number of paths for the other directions is quite homogeneous. In Fig. 5b we show the azimuthal distribution of the interstation paths (in both causal and acausal directions) for 
which we have obtained dispersion measurements, at different periods $(10,20$ and $25 \mathrm{~s})$ and for different time periods: the entire year 2008, the 3 winter months (January to March) and the 3 summer months (July to September). For the $10 \mathrm{~s}$ period there is a predominance of paths with high SNR in the NNW-SSE directions for the entire year and winter months, but not for the summer months. This indicates that for short periods the larger source of ambient noise is winter storms in the North Atlantic. For periods of 20 and $30 \mathrm{~s}$ the azimuthal distribution of cross-correlations with high SNR is quite homogeneous for winter, summer and the entire year. The simulations run by Yang and Ritzwoller (2008) indicate that with azimuthal distributions as those shown in Fig. 5 the accuracy of the empirical Green's functions and the dispersion measurements is adequate for ambient noise tomography.

Group and phase velocity dispersion curves were inverted for different periods in order to obtain maps of group and phase velocity lateral variations. The perturbations are computed with respect to the map average velocity $V_{\text {ref }}$ and expressed in percentage.

The results of group and phase velocities for the period of $10 \mathrm{~s}$ are presented in Fig. 6.

Rayleigh waves for this period are sensitive mostly to structures shallower than $15 \mathrm{~km}$, as can be seen in their depth sensitivity kernels (Fig. 6c). While the sensitivity for $10 \mathrm{~s}$ group velocity is relatively narrow and peaks at approximately $7 \mathrm{~km}$ depth, the sensitivity for $10 \mathrm{~s}$ phase velocity is broader and peaks at $10 \mathrm{~km}$ depth.

Fig. 7 summarizes the group velocities obtained for selected periods of 8,20 and $30 \mathrm{~s}$ (see Fig. $6 \mathrm{c}$ for their depth sensitivities). At shorter periods, below $8 \mathrm{~s}$, the map displays a good correlation with the surface tectonics, while for periods greater than $30 \mathrm{~s}$ the anomalies start fading.

For comparison, we have computed synthetic Rayleigh-wave group velocities for models previously obtained by other authors. Most of the models were taken from seismic studies carried out under the scope of ILIHA project (ILHA DSS Group, 1993) and earlier. A compilation of the existing P-wave velocity models can be found in Matias (1996). To estimate $S$-wave velocities we used a value of 1.75 for the $V_{\mathrm{P}} / V_{\mathrm{S}}$ ratio for this region and a density derived from Birch's law. The different dispersion curves have been superimposed to the average group velocities obtained for the Iberian Massif and presented in Fig. 8. We display, as a reference, the ILIHA lines used to compute the synthetics. As we can see in Fig. 8, our results fit quite well the synthetic dispersion curves.

\section{Discussion}

With respect to the previous work by Villaseñor et al. (2007), the inclusion of seismic stations in Portugal, Northern Morocco and Canary islands has expanded the covered area to western Iberia and to the Gibraltar Strait area. Most of the main features already observed Villaseñor et al. (2007) are present in the current work, but the large increase on ray-paths allows a better definition of the lateral extent of these features and of their small-scale structure. Moreover, some of the sharp discontinuities previously found were due to a smearing effect clearly associated to the station distribution, the additional travel-paths in this work smooth some of those anomalies. At short periods, the group-velocity maps (Figs. 6a and 7a) display a good correlation with the surface expression of the main structural units. The most prominent feature is the vast high-velocity anomaly that covers Western Iberia, defining the core of the Iberian Massif (Fig. 1). It can be followed from the $8 \mathrm{~s}$ map to the last period inverted (Fig. 7c). Analysis of the maps presented in Fig. 7 allows us to define and establish the limits of the Iberian Massif.

South of the Massif, the Cadiz Gulf and Gibraltar Strait areas correspond to a strong low-velocity anomaly, which can be followed up to the largest period inverted (30 s), which correspond roughly to 40-45 km depth, although slightly shifted to the east at longer periods. Adding stations from Morocco and Canary Islands enabled us to better resolve seismic anomalies for periods greater than $18 \mathrm{~s}$. This outcome confirms and extends the results from Villaseñor et al. (2007). Although on the edge of resolution, we also detect, at shorter periods, the presence of the Algarve Basin, although the associated anomaly transition is affected by the low-velocity anomaly of the Cadiz Gulf.

To the southeast of the Iberian Massif, we can identify a well-defined boundary with the Guadalquivir basin and eastern external Betics, revealed by a large contrast from positive to negative velocity anomalies that can be observed in almost all periods.

To the east, in 8 and $10 \mathrm{~s}$ maps, Alpine orogens (Iberian and Betic ranges) show small relative high-velocity anomalies in group-velocity maps that are no longer visible at longer periods. This may reveal the shallow extent of the igneous and Paleozoic rocks of those chains, while the low-velocity anomalies in the long-period group velocities are due to the crustal roots of those mountain ranges. a

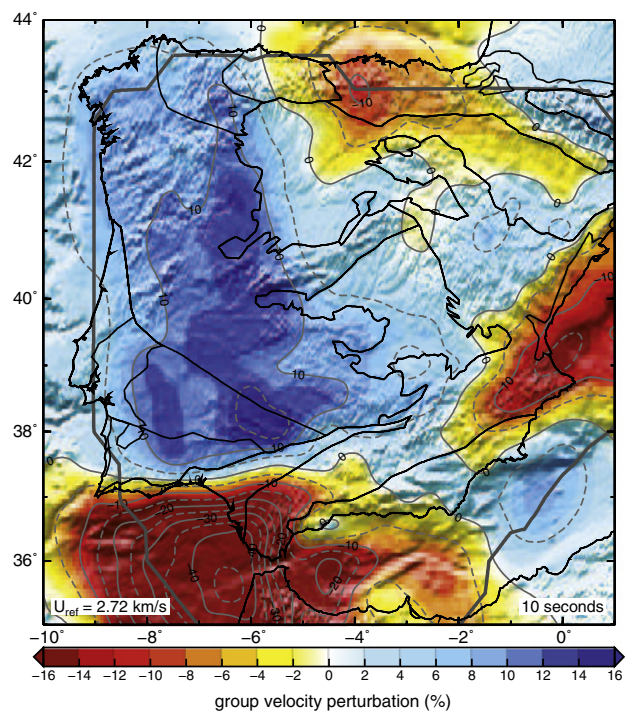

b

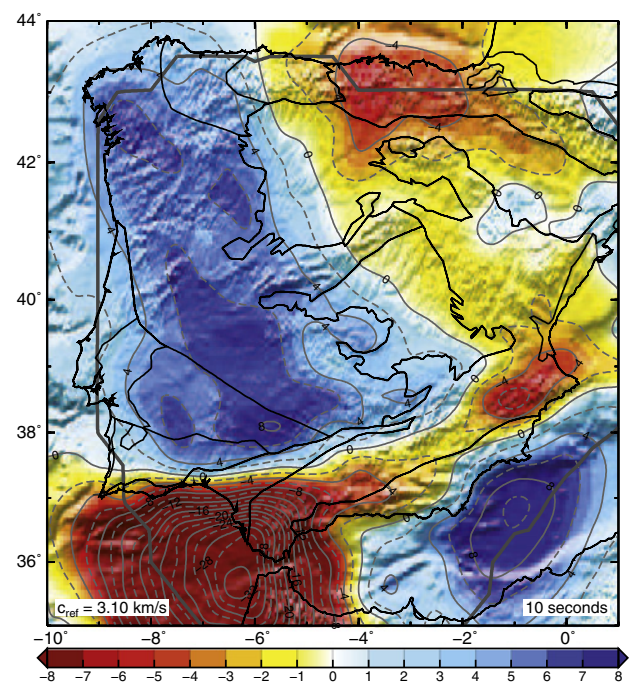

C

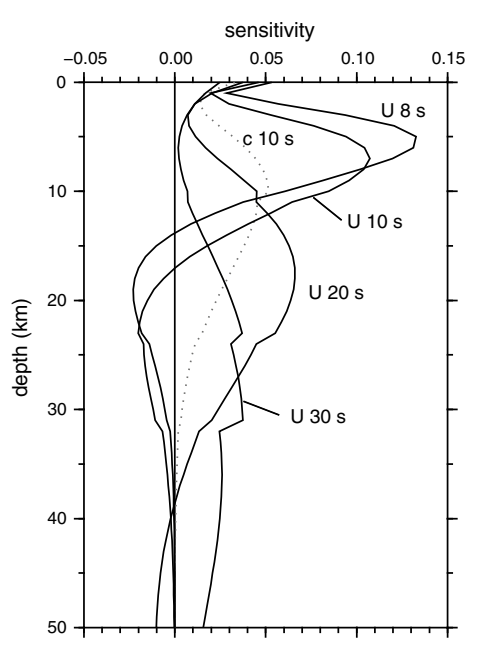

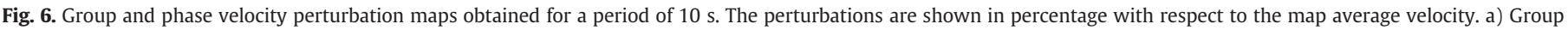

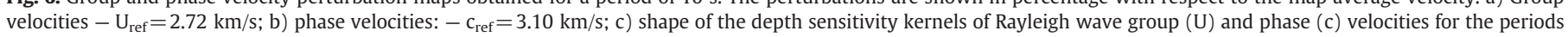
of the maps shown in this figure and Fig. 7. 

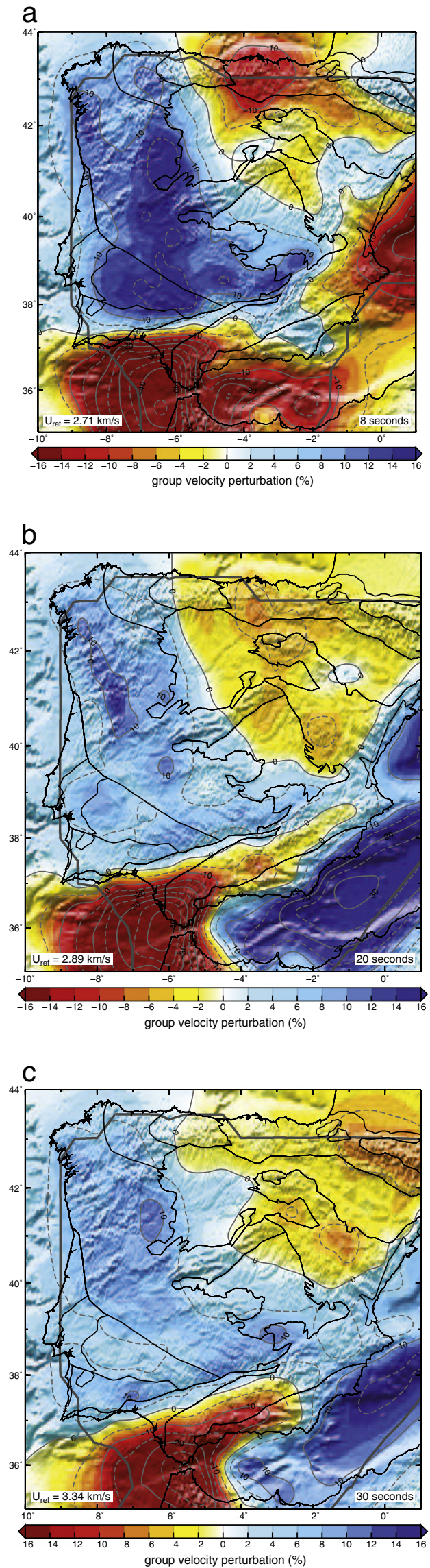

Fig. 7. Group velocity perturbation maps for: a) $\mathrm{T}=8 \mathrm{~s}, \mathrm{U}_{\mathrm{ref}}=2.71 \mathrm{~km} / \mathrm{s}$; b) $\mathrm{T}=20 \mathrm{~s}$, $\left.\mathrm{U}_{\mathrm{ref}}=2.89 \mathrm{~km} / \mathrm{s} ; \mathrm{c}\right) \mathrm{T}=30 \mathrm{~s}, \mathrm{U}_{\mathrm{ref}}=3.34 \mathrm{~km} / \mathrm{s}$.
With a variable degree of distinction, the several units described or their contacts are present on the gravity (Corchete et al., 2005) and magnetic (Silva et al., 2000) fields. For comparison we superimposed the contour of the Iberian Massif, obtained from all the group-velocity maps, to both tectonic and gravimetric anomaly maps (Fig. 9). The correlation with the tectonic map is striking (Fig. 9a). Although less clear in the western part, we also attained a good correlation with the gravimetric anomalies (Fig. 9b).

Our models reveal a first-order homogeneous Massif. Nonetheless, it is possible to identify some second-order anomalies inside this area. With exception of the Cantabrian Zone, which has no clear expression in our maps, the contact between the several tectonic units composing the massif can be recognized with the outline of the anomalies following the shape of the Ibero-Armorican arc.

At shorter periods (Figs. 6 and 7a) we can notice higher velocities in the northern part of Portugal, related to the Galicia-Trás-os-Montes Zone, which can be followed up to the largest period inverted (30 s). When the period increases this anomaly slightly decreases but a higher velocity is still visible beneath the Morais-Bragança massif (southeastern GTMZ). To the west, at $30 \mathrm{~s}$, and although slightly shifted, we can still observe a small anomaly which can be related to the Ordoñes Massif. The high velocity anomalies associated with the CIZ decrease from NW to SE, but are still sharp enough to distinguish from the OMZ.

In the shorter period maps, the OMZ shows strong high-velocity anomalies relative to both CIZ and SPZ, namely beneath Sierra Morena in the SW contact with the Guadalquivir basin. For longer-periods there is an inversion in this pattern, with the OMZ showing slower velocities or even no contrast with CIZ and SPZ, suggesting a deeper contact between these two later tectonic units, as suggested by Matias (1996). The high-velocity anomaly in the contact between the OMZ and the Lower-Tagus and Sado basin can be interpreted as the root of the core of Variscan igneous rocks.

The western boundary of the Iberian Massif is clearly seen in all maps, in particular the contact with the Lusitanian Basin. This basin, associated with the Atlantic Meso-Cenozoic rifting episodes, can be followed even beneath the sediments of the Lower Tagus-Sado basin, clearly defining the limits of both the CIZ and the OMZ. For the SPZ such conclusion cannot be drawn, since southwestern SPZ lies outside the sampled area.

In our maps, there is no significant signature of the Douro/Duero and Tagus sedimentary basins (DB and TB) and from the Central Range. This poor correlation may suggest the shallow character of those structures and that, in fact, we are imaging the structures beneath those basins.

\section{Conclusions}

In this work, we present a high-resolution image of western Iberia using surface waves at short periods that would have been impossible to carry out with earthquakes alone. At a first degree, maps of both phase and group velocity lateral variations reveal the presence on a homogeneous Iberian Massif, characterized by a strong positive anomaly, still observable at $30 \mathrm{~s}$, corresponding roughly to $40-$ $50 \mathrm{~km}$ depth. The boundaries of this core of the Iberian Peninsula are clearly visible at all periods inverted. Analysis of the second order anomalies allow to detect smaller structures within the Massif, namely the high velocities in the north (GTMZ) perceptible to the highest period inverted and the occurrence of lower velocities in the Ossa-Morena zone in the 20-second map. The signature of the Meso-Cenozoic basins is clearly defined, especially in western Iberia. Although on the edge of resolution, the Cadiz Gulf corresponds to a very significant negative anomaly noticeable at all periods.

\section{Acknowledgments}

We thank the Instituto Geográfico Nacional (Spain) and the Instituto de Meteorologia (Portugal) for providing the waveform data from their 


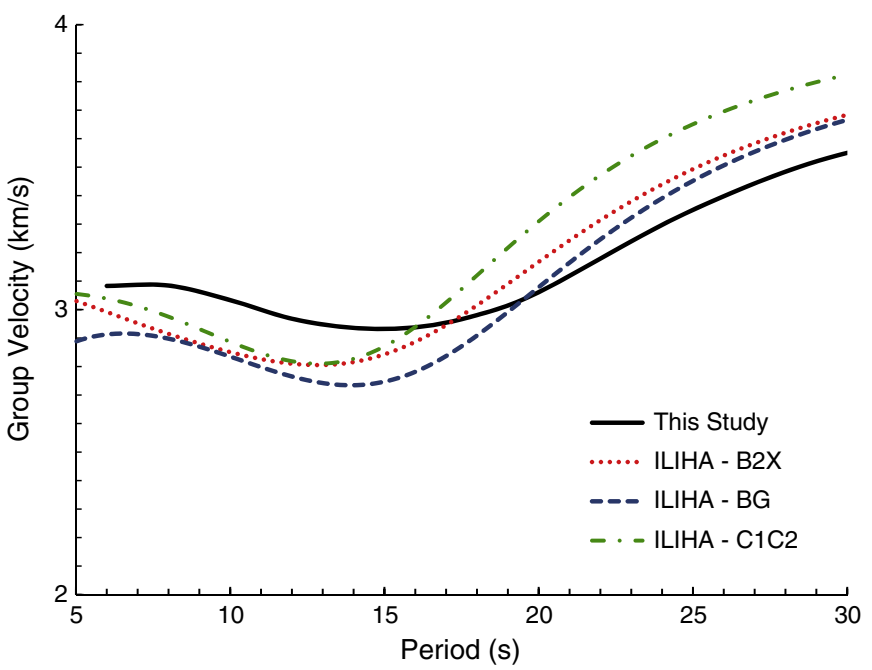

Fig. 8. Averaged group velocities for the Iberian Massif superimposed with synthetic Rayleigh-wave group velocities computed for other models in the area.

national seismic networks that are the base of this study. We also thank the Real Instituto y Observatorio de la Armada (Spain), and the data centers of ORFEUS (The Netherlands), GEOFON (Germany) and IRIS (USA) for providing data from other broadband stations in the region. Fruitful

a

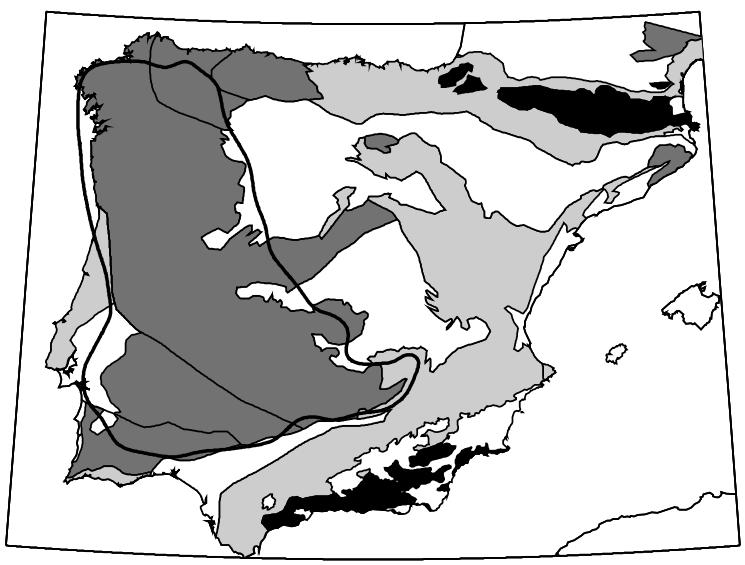

b

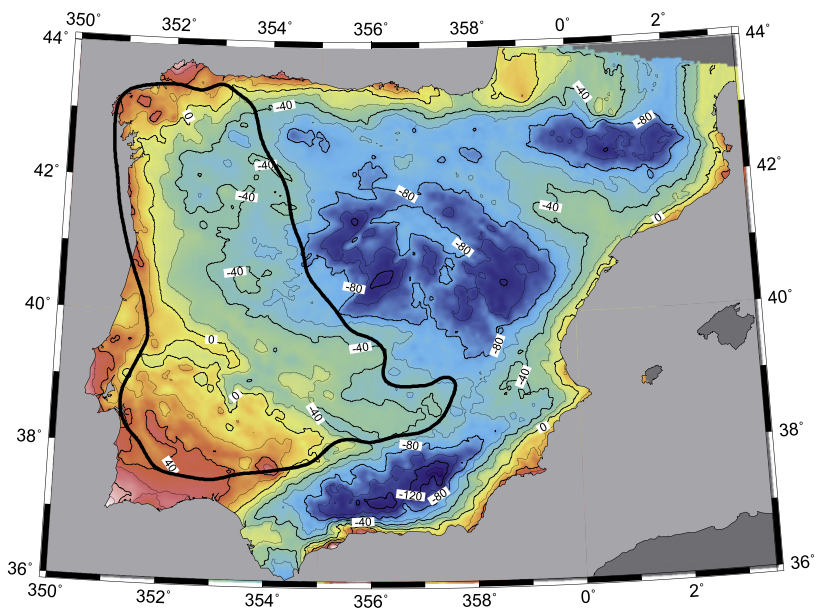

Fig. 9. a) Average boundary of the Iberian Massif obtained from the dispersion maps superimposed to: a) tectonic units as already displayed in Fig. 1; b) Bouguer gravity anomalies adapted from Mezcua et al. (1996). discussions with Luis Matias are gratefully acknowledged. The authors would like to thank Deyan Draganov and the anonymous reviewer for their valuable revision and suggestions to improve the quality of the paper. This study was funded by a joint effort of Fundação para a Ciência e a Tecnologia (Portugal)-CSIC (Spain) project (FCT Ref. 20/CSIC/08; CSIC Ref. 2007PT0006) and TOPOMED (TOPOEUROPE/ 0001/2007). The work was also partially supported by WILAS project (PTDC/CTE-GIX/097946/2008). This is a contribution to PEST-OE/CTE/ LA0019/2011 - IDL and of the Team Consolider-Ingenio 2010 CSD2006-00041 (TOPO-IBERIA).

\section{References}

Afilhado, A., Matias, L., Shiobara, H., Hirn, A., Mendes-Victor, L., Shimamura, H., 2008. From unthinned continent to ocean: the deep structure of the West Iberia passive continental margin at $38^{\circ} \mathrm{N}$. Tectonophysics 458, 9-50.

Badal, J., Corchete, V., Payo, G., Serón, F.J., Canas, J.A., Pujades, L., 1992. Deep structure of the Iberian Peninsula determined by Rayleigh wave velocity inversion. Geophysical Journal International 108, 71-88.

Badal, J., Corchete, V., Payo, G., Canas, J.A., Pujades, L., 1993. Shear wave velocity structure below the Iberian Peninsula as obtained by a detailed analysis of surface waves. Tectonophysics 225, 167-190.

Badal, J., Corchete, V., Payo, G., Canas, J.A., Pujades, L., 1996. Imaging of shear-wave velocity structure beneath Iberia. Geophysical Journal International 124, 591-611.

Barmin, M., Ritzwoller, M.H., Levshin, A.L., 2001. A fast and reliable method for surface wave tomography. Pure and Applied Geophysics 158, 1351-1375.

Bensen, G.D., Ritzwoller, M.H., Barmin, M.P., Levshin, A.L, Lin, F.-C, Moschetti, M.P. Shapiro, N.M., Yang, Y., 2007. Processing seismic ambient noise data to obtain reliable broad-band surface wave dispersion measurements. Geophysical Journal International 169, 1239-1260.

Borges, J.F., Fitas, A.J.S., Bezzeghoud, M., Teves-Costa, P., 2001. Seismotectonics of Portugal and its adjacent Atlantic area. Tectonophysics 331, 373-387.

Canas, J.A., de Miguel, F., Vidal, F., Alguacil, G., 1988. Anelastic Raleigh waves attenuation in the Iberian Peninsula. Geophysical Journal of the Royal Astronomical Society 95, 391-396.

Carbonell, R., Simancas, J.F., Juhlin, C., Pous, J., Pérez-Estaún, A., González-Lodeiro, F., Muñoz, G., Heise, W., Ayarza, P., 2004. Geophysical evidence of a mantle derived intrusion in SW Iberia. Geophysical Research Letters 31, L11601.

Corchete, V., Badal, J., Pujades, L., Canas, J.A., 1993. Shear-velocity structure beneath the Iberian Massif from broadband surface wave data. Physics of the Earth and Planetary Interiors 79, 349-365.

Corchete, V., Badal, J., Serón, FJ., Soria, A., 1995. Tomographic images of the Iberian subcrustal lithosphere and asthenosphere. Journal of Geophysical Research 100, 24133-24146.

Corchete, V., Chourak, M., Khattach, D., 2005. The high-resolution gravimetric geoid of Iberia: IGG2005. Geophysical Journal International 162, 676-684.

da Silva, N.V., Mateus, A., Santos, F.A.M., Almeida, E.P., Pous, J., 2007. 3-D electromagnetic imaging of a Palaeozoic plate-tectonic boundary segment in SW Iberian Variscides (S AlenteJo, Portugal). Tectonophysics 445, 98-115.

Dias, R., Ribeiro, A., 1995. The Ibero-Armorican Arc: a collision effect against an irregular continent? Tectonophysics 246, 113-128.

Díaz, J., Gallart, J., 2009. Crustal structure beneath the Iberian Peninsula and surrounding waters: a new compilation of deep seismic sounding results. Physics of the Earth and Planetary Interiors 173, 181-190.

Fernández, M., Marzan, I., Torné, M., 2004. Lithospheric transition from the Variscan Iberian Massif to the Jurassic oceanic crust of the Central Atlantic. Tectonophysics 386, 97-115. 
García-Navarro, E., 2004. Final stages of the Variscan orogeny at the southern Iberian massif: lateral extrusion and rotation of continental blocks. Tectonics 23, TC6001.

Gonzalez, A., Torne, M., Cordoba, D., Vidal, N., Matias, L.M., Diaz, J., 1996. Crustal thinning in the Southwestern Iberia Margin. Geophysical Research Letters 23, 2477-2480.

Gonzalez-Fernandez, A., Cordoba, D., Matias, L.M., Torne, M., 2001. Seismic crustal structure in the Gulf of Cadiz (SW Iberian Peninsula). Marine Geophysical Research 22, 207-223.

ILHA DSS Group, 1993. A deep seismic sounding investigation of lithospheric heterogeneity and anisotropy beneath the Iberian Peninsula. Tectonophysics 221, 35-51.

Lana, X., Fernández Mills, G., Badal, J., Canas, J.A., 1997. Objective regionalisation of Rayleigh wave dispersion data by clustering algorithms. Geophysical Journal International 129, 421-438.

Lana, X., Caselles, O., Canas, J.A., Badal, J., Pujades, L., Martínez, M.D., 1999. Anelastic structure of the Iberian Peninsula from an automated regionalisation algorithm and stochastic inversion. Tectonophysics 304, 219-239.

Levshin, A., Ratnikova, L., Berger, J., 1992. Peculiarities of surface-wave propagation across Central Eurasia. Bulletin of the Seismological Society of America 82, 2464-2493.

Martinez, M.D., Lana, X., Caselles, O., Canas, J.A., Pujades, L., 2005. Elastic-anelastic regional structures for the Iberian peninsula obtained from Rayleigh wave tomography and causal uncoupled inversion. Pure and Applied Geophysics 162, 2321-2353. http://dx.doi.org/10.1007/s00024-005-2778-4.

Matias, L.M., 1996. A sismologia experimental na modelação da estrutura da crusta em Portugal continental, Ph.D. thesis. Univ. of Lisbon, 398 pp.

Mezcua, J., Gil, A., Benarroch, R., 1996. Estudio gravimétrico de la Peninsula Iberica y Baleares. Inst. Geogr. Nac.19 pp., 2 sheets.

Muñoz, G., Mateus, A., Pous, J., Heise, W., Monteiro Santos, F., Almeida, E., 2008. Unraveling middle-crust conductive layers in Paleozoic Orogens through 3D modeling of magnetotelluric data: the Ossa-Morena Zone case study (SW Iberian Variscides). Journal of Geophysical Research 113, B06106.

Onézime, J., Charvet, J., Faure, M., Bourdier, J.-L., Chauvet, A., 2003. A new geodynamic interpretation for the South Portuguese Zone (SW Iberia) and the Iberian Pyrite Belt genesis. Tectonics 22, 1027.
Payo, G., Corchete, V., Badal, J., Serón, F.J., Canas, J.A., Pujades, L., 1992. First two station Rayleigh wave velocity measurements for the Northern Iberia Region. Bulletin of the Seismological Society of America 82, 1434-1452.

Ritzwoller, M.H., Shapiro, N.M., Barmin, M.P., Levshin, A.L., 2002. Global surface wave diffraction tomography. Journal of Geophysical Research 107, 2335.

Santos, F.A.M., Pous, J., Almeida, E.P., Queralt, P., Marcuello, A., Matias, H., Victor, L.A.M., 1999. Magnetotelluric survey of the electrical conductivity of the crust across the Ossa Morena Zone and South Portuguese Zone suture. Tectonophysics 313, 449-462.

Santos, F.A.M., Mateus, A., Almeida, E.P., Pous, J., Mendes-Victor, L.A., 2002. Are some of the deep crustal conductive features found in SW Iberia caused by graphite? Earth and Planetary Science Letters 201, 353-367.

Silva, E.A., Miranda, J.M., Luis, J.F., Galdeano, A., 2000. Correlation between the Palaeozoic structures from West Iberian and Grand Banks margins using inversion of magnetic anomalies. Tectonophysics 321, 57-71.

Simancas, J.F., Poyatos, D., Expósito, I., Azor, A., González-Lodeiro, F., 2001. The structure of a major suture zone in the SW Iberian Massif: the Ossa-Morena/Central Iberian contact. Tectonophysics 332, 295-308.

Simancas, J.F., Carbonell, R., González-Lodeiro, F., Pérez-Estaún, A., Juhlin, C., Ayarza, P. Kashubin, A., Azor, A., Martínez Poyatos, D.J., Almodóvar, G.R., Pascual, E., Sáez, R. Expósito, I., 2003. Crustal structure of the transpressional Variscan orogen of SW Iberia: SW Iberia deep seismic reflection profile (IBERSEIS). Tectonics 22, 1062.

Vergés, J., Fernàndez, M., 2006. Ranges and Basins in the Iberian Peninsula: their contribution to the present topography. In: Gee, D., Stephenson, R. (Eds.), European Lithosphere Dynamics (Geological Society Memoir), vol. 32, pp. 223-234.

Villaseñor, A., Yang, Y., Ritzwoller, M.H., Gallart, J., 2007. Ambient noise surface wave tomography of the Iberian Peninsula: implications for shallow seismic structure. Geophysical Research Letters 34, L11304.

Yang, Y., Ritzwoller, M.H., 2008. Characteristics of ambient seismic noise as a source for surface wave tomography. Geochemistry, Geophysics, Geosystems 9, Q02008. http://dx.doi.org/10.1029/2007GC001814. 